\section{(1) \\ CrossMark}

\title{
Asthma-COPD overlap: current understanding and the utility of experimental models
}

\author{
Xiaofan Tu, ${ }^{1,4}$, Chantal Donovan ${ }^{1,2,3,4}$, Richard Y. Kim², ${ }^{1,2,3}$, Peter A.B. Wark (1) \\ Jay C. Horvat ${ }^{1}$ and Philip M. Hansbro ${ }^{1,2,3}$
}

Affiliations: ${ }^{1}$ Priority Research Centre for Healthy Lungs, Hunter Medical Research Institute, University of Newcastle, Newcastle, Australia. ${ }^{2}$ Centre for Inflammation, Centenary Institute, Camperdown, Australia. ${ }^{3}$ University of Technology Sydney, School of Life Sciences, Faculty of Science, Sydney, Australia. ${ }^{4}$ Both authors contributed equally.

Correspondence: Philip M. Hansbro, Centre for Inflammation, Centenary Institute, Building 93, Royal Prince Alfred Hospital, Missenden Road, Camperdown, NSW 2050, Australia. E-mail: p.hansbrodacentenary.org.au

@ERSpublications

Understanding the pathogenesis of asthma-COPD overlap is critical for improving therapeutic approaches. We present current knowledge on asthma-COPD overlap and the requirements for developing an optimal animal model of disease. https://bit.ly/3lsjyvm

Cite this article as: Tu X, Donovan C, Kim RY, et al. Asthma-COPD overlap: current understanding and the utility of experimental models. Eur Respir Rev 2021; 30: 190185 [https://doi.org/10.1183/ 16000617.0185-2019].

ABSTRACT Pathological features of both asthma and COPD coexist in some patients and this is termed asthma-COPD overlap (ACO). ACO is heterogeneous and patients exhibit various combinations of asthma and COPD features, making it difficult to characterise the underlying pathogenic mechanisms. There are no controlled studies that define effective therapies for ACO, which arises from the lack of international consensus on the definition and diagnostic criteria for ACO, as well as scant in vitro and in vivo data. There remain unmet needs for experimental models of ACO that accurately recapitulate the hallmark features of ACO in patients. The development and interrogation of such models will identify underlying disease-causing mechanisms, as well as enabling the identification of novel therapeutic targets and providing a platform for assessing new ACO therapies. Here, we review the current understanding of the clinical features of ACO and highlight the approaches that are best suited for developing representative experimental models of ACO.

\section{Introduction}

Asthma and COPD are prevalent chronic respiratory diseases driven by complex interactions between intrinsic and extrinsic factors that result in a wide spectrum of clinical presentations [1-4]. Despite clear differences in their aetiology and pathophysiology $[5,6]$, differentiating asthma and COPD at a diagnostic level is often challenging, particularly as analyses of patient spirometry data and inflammatory markers frequently identify obstructive airway disease phenotypes that encompass a mix of asthma and COPD features $[7,8]$. Presently, this patient group is referred to as patients with asthma-COPD overlap (ACO) $[9,10]$ and is estimated to encompass $11.1-61.0 \%$ of the 339 million patients with asthma and $4.2-66.0 \%$ of the 252 million patients with COPD, worldwide $[11,12]$. Individuals with ACO have increased disease severity [13], poorer quality of life [14] and incur higher healthcare costs when compared with patients with asthma or COPD alone [15]. Notably, patients with ACO are excluded from the majority of asthma

Provenance: Submitted article, peer reviewed

Received: 23 Dec 2019 | Accepted: 3 Nov 2020

Copyright $\odot$ ERS 2021. This article is open access and distributed under the terms of the Creative Commons Attribution Non-Commercial Licence 4.0. 
and COPD randomised control trials, which contributes to the lack of efficacy and safety data on effective therapies for patients with ACO. This, in combination with the limited number of specific interventional studies in cohorts of patients with ACO, has resulted in a lack of knowledge of effective treatment strategies.

Here we review $\mathrm{ACO}$ as an emerging and distinct category of obstructive airway disease phenotypes and discuss potential avenues for research. We highlight the limitations of using ACO as a diagnostic label and examine alternative approaches for improved therapeutic targeting of specific disease features. Few evidence-based treatments are currently available for patients with ACO due to a shortage of human clinical studies and animal models that can be used to rigorously test the effectiveness of potential therapies. We thereby discuss the requirements for animal models that recapitulate the cardinal features of human ACO and how they may be used to improve the understanding of underlying disease-causing mechanisms, identification of novel therapeutic targets, and development of more effective treatments.

\section{Characteristics of ACO}

Chronic airway inflammation is a key component of ACO and is linked to airway remodelling, airflow obstruction, as well as subsequent symptoms of disease including wheezing and dyspnoea that worsen during acute exacerbations $[10,16]$. In addition, various cardinal features of mild/moderate allergic asthma (reversible airflow limitation and eosinophilic/type-2 inflammation) and COPD (irreversible airflow limitation and neutrophilic/type-1/-17 inflammation) frequently coalesce in patients with ACO [17]. This is evidenced by findings of overlap clusters in studies that have recruited both asthma and patients with COPD (table 1). Recurring characteristics of the overlap cluster included moderate-to-severe non-fully reversible airflow obstruction, peak flow variability or airway hyperresponsiveness (AHR) and presence of atopy in terms of elevated serum IgE. However, different clusters of patients with ACO demonstrated differences in severity of airflow obstruction, pack-years of smoking, and numbers/percentages of neutrophils and eosinophils in sputum and blood. These phenotypic variations should be validated in larger cohorts to mitigate the effects of sampling techniques, but ACO manifests as a spectrum of clinical and pathophysiological features, which is becoming increasingly apparent given the heterogeneity of both asthma and COPD. This means that patients should not be given homogenous treatments and that therapies tailored to subgroups/clusters should be prioritised instead. In addition, while certain disease features such as the extent and location of airway remodelling is known to differ between asthma and COPD [26], how they are altered or combined in ACO remain to be explored in depth. Interestingly, in one study where the cluster of patients with ACO was subdivided into patients with ACO-asthma and patients with ACO-COPD based on the initial diagnosis, a higher percentage of patients with ACO-asthma were admitted to emergency departments and intensive care units than patients with ACO-COPD, despite similar spirometry results [25]. This suggests a further stratification of patients who progress from asthma to ACO versus those from COPD to ACO and the differences in their underlying mechanisms is of interest for future studies.

\section{Current definitions and diagnostic criteria}

Currently, there is no universally accepted definition of ACO, primarily owing to its heterogeneity. Several national guidelines, as well as the joint document from the Global Initiative for Asthma (GINA) and COPD (GOLD), only provide generalised descriptions of ACO [27-30]. The Spanish Guidelines on the Management of Asthma (GEMA) and COPD (GesEPOC) define ACO as the presence of asthmatic features in conjunction with irreversible airflow obstruction in a smoker or former smoker [31]. While this provides a more selective framework for designing protocols to trial treatments, it excludes individuals whose COPD originates from other environmental pollutants and fails to acknowledge that many smokers do not develop COPD, therefore smoking history alone should not be the only surrogate marker for COPD. Thus, the optimal definition of ACO should balance sufficient specificity in order to be clinically useful, with a broad range of criteria to ensure potentially important groups are not inappropriately excluded. However, and as discussed by others, this may be unachievable as ACO likely encompasses a wide spectrum of phenotypes, e.g. patients with COPD with eosinophilia and partially reversible airflow limitation versus patients with severe asthma with neutrophilia and fixed airflow limitation, or elderly nonsmokers with long-standing asthma and irreversible airflow limitation [32-35]. Therefore, in order to progress our understanding of ACO, and to develop optimal treatment strategies, there is an urgent need for new markers and/or classification criteria that enable additional sub-categorisation of patients with ACO. In the interim, ACO studies may benefit from stratifying patients based on the severity of their airflow limitation, similar to the stages of COPD (GOLD initiative guidelines), as a means of optimising treatment levels and monitoring outcomes.

For diagnosis, GINA/GOLD guidelines recommend a checklist approach to identify concurrent asthma and COPD features [27]. In contrast, GEMA/GesEPOC proposed stepwise approaches requiring an initial 
TABLE 1 Studies indicating an overlap phenotype that included both asthma and COPD patients in cluster analysis

\begin{tabular}{|c|c|c|c|c|}
\hline Subjects & $\begin{array}{l}\text { Total } \\
\text { identified } \\
\text { clusters }\end{array}$ & $\begin{array}{l}\text { Overlap } \\
\text { cluster }\end{array}$ & Overlap cluster characteristics & $\begin{array}{l}\text { First author } \\
\text { [ref.] }\end{array}$ \\
\hline $\begin{array}{l}175 \text { participants: Wellington Respiratory } \\
\text { Survey }\end{array}$ & 5 & $15(8.6)$ & $\begin{array}{l}\text { Severe airflow obstruction } \\
\text { Greatest post-bronchodilator reversibility and } \\
\text { peak flow variability } \\
\uparrow \text { Pack-years smoking history } \\
\uparrow \text { Serum IgE and peripheral blood eosinophils } \\
\text { and high prevalence of eczema and rhinitis } \\
\text { Chronic sputum production } \\
\uparrow \text { Prevalence of macroscopic emphysema }\end{array}$ & Weatherall [19] \\
\hline $\begin{array}{l}389 \text { subjects with symptoms of wheeze and } \\
\text { breathlessness in last } 12 \text { months }\end{array}$ & 5 & $34(8.7)$ & $\begin{array}{l}\text { Severe airflow obstruction } \\
\text { High post-bronchodilator reversibility and } \\
\quad \text { peak flow variability } \\
\downarrow F_{\text {eNO }} \\
\uparrow \text { Serum IgE } \\
\text { High pack-years smoking history } \\
\uparrow \text { Neutrophil count and } \downarrow \text { eosinophil count in } \\
\quad \text { blood }\end{array}$ & FINGLETON [21] \\
\hline $\begin{array}{l}152 \text { patients with asthma and } 50 \text { patients } \\
\text { with COPD }\end{array}$ & 4 & $50(24.8)$ & $\begin{array}{l}\text { High pack-years smoking history } \\
\text { Airflow obstruction intermediate to COPD and } \\
\text { asthma clusters } \\
\text { High prevalence of atopy and } \uparrow \text { serum IgE, } \uparrow \\
\text { peripheral blood eosinophils and } \uparrow F_{\mathrm{eNO}}\end{array}$ & HIRAI [24] \\
\hline $\begin{array}{l}877 \text { patients with asthma and } 228 \text { patients } \\
\text { with COPD: French national Bronchial } \\
\text { Obstruction and Asthma Cohort }\end{array}$ & 3 & $386(34.9)$ & $\begin{array}{l}\text { Worse airflow obstruction than asthma } \\
\text { cluster but better compared with COPD } \\
\text { cluster } \\
\uparrow \text { Post-bronchodilator reversibility }\end{array}$ & BouRdIN [25] \\
\hline
\end{tabular}

Data are presented a $\mathrm{n}(\%)$, unless otherwise stated. Ig: immunoglobulin; IL: interleukin; TNF- $\alpha$ : tumour necrosis factor- $\alpha$; $F_{\mathrm{eNO}}$ : fractional exhaled nitric oxide. 
diagnosis of COPD (aged $>35$ years, history of smoking, and post-bronchodilator forced expiratory volume in $1 \mathrm{~s}\left(\mathrm{FEV}_{1}\right) /$ forced vital capacity $\left.(\mathrm{FVC})<0.70\right)$, followed by either a diagnosis of asthma or demonstration of a type-2 inflammatory profile [31,36]. Alternatively, and as previously reviewed [10], multiple diagnostic proposals have utilised a combination of major and minor criteria that describe essential primary and secondary disease features [37-41]. A recent study incorporated elements of this approach by tracking features such as persistent airflow limitation, 40 years of age or older, a history of asthma during early life, and significant smoke exposure ( $\geqslant 10$ pack-years) [40]. Importantly, there remains no global consensus on appropriate diagnostic criteria for ACO, and the implementation of different criteria among epidemiologic studies has produced significant variations in reported statistics for disease prevalence and outcomes [12,42,43]. These limitations are intrinsic to the conventional systems of disease labelling, which may be addressed by incorporating elements of the treatable traits strategy to characterise the complexity and heterogeneity of ACO.

\section{Treatable traits}

The treatable traits concept proposed by AGUSTI et al. [44] promises therapeutic precision using individual pheno/endotypic features, rather than the traditional assignment of disease labels. This multi-dimensional strategy of examining pulmonary, extrapulmonary, and behavioural/psychosocial traits has been trialled in two cross-sectional asthma studies $[45,46]$, with the results showing that higher numbers of identifiable traits correspond to more severe disease, and that specific traits (such as eosinophilic inflammation) are associated with more frequent exacerbations $[45,46]$. While the therapeutic benefits of targeting specific traits remain to be assessed, this label-free approach of delivering precision medicine to heterogeneous obstructive airway diseases may eliminate the need for/use of umbrella terms such as ACO [47, 48]. However, full implementation of the treatable traits system in primary and specialised care settings requires the rigorous process of generating a high-quality evidence base. One way forward is to trial the incorporation of elements of the treatable traits approach into the current clinical practise in order to improve diagnostic resolution/sensitivity of existing methods, while retaining indispensable elements of the current system i.e. spirometry. There are strong arguments for the continued use of the descriptor ACO in the interim to: 1) distinguish patients with overlapping features from classic asthma and patients with COPD; and 2) promote human and animal studies of the overlap to elucidate underlying disease mechanisms and identify the most effective treatment strategies.

\section{Biomarkers}

Biomarkers are a key component of the treatable traits concept, and are increasingly utilised in assessing treatment options as well as in the diagnosis and monitoring of obstructive airway diseases [44, 49]. Biomarkers including fractional exhaled nitric oxide [38, 41], eosinophil counts in peripheral blood [39-41] or sputum $[37,38,41]$ and serum IgE levels [37-39, 41] have been investigated across different cohorts of patients with ACO. Blood eosinophil counts have been identified as a predictor of response to inhaled corticosteroid (ICS) treatment in COPD [50-52]. Consequently, the 2019 GOLD guidelines recommend ICS treatment for patients with COPD with blood eosinophil count $\geqslant 300$ cells $\mu \mathrm{L}^{-1}$ (and consider ICS treatment for 100-300 cells $\mu \mathrm{L}^{-1}$ ); however, blood eosinophil count data needs to take into account exacerbation severity and frequency for accurate interpretation [6]. Recently, SHIRAI et al. [53] reported that serum periostin, associated with type-2 eosinophilic inflammation, is significantly elevated in ACO-asthma, whereas YKL-40, a chitinase-like protein involved in airway inflammation and remodelling [54, 55], is significantly elevated in patients with ACO-COPD [56]. However, conflicting data for the expression of periostin [57, 58] or YKL-40 [59] in patients with ACO necessitates further studies to clarify their sensitivity/reliability as biomarkers. Finally, increased sputum levels of neutrophil gelatinase-associated lipocalin has shown promise as an ACO-specific marker [60-62]. Taken together, there remains a strong need for interventional studies that rigorously examine the diagnostic and/or therapeutic potential of bona fide ACO biomarkers. Such studies should also address current limitations relating to the lack of homogenous treatments in existing ACO studies that may cloud the interpretation and evaluation of biomarkers.

\section{Endotypes}

Endotypes refer to disease subtypes with specific mechanisms implicated in pathogenesis [63] and are considered to be amenable to precision medicine approaches [44]. This review does not exhaustively evaluate all known endotypes of obstructive airway diseases, but rather highlights areas that are suitable for investigation in future ACO studies. Type-2 responses (i.e. IL-4/-5/-13) and eosinophilic inflammation are widely regarded as a critical mechanism underlying certain asthma endotypes [63, 64] and can be suppressed with targeted therapy [65]. A comprehensive panel of candidate genes that define potential asthma endotypes can also be assessed in ACO studies [66]. Interestingly, upregulated expression of asthma-associated type- 2 inflammatory genes have been identified in subgroups of patients with COPD and are linked to more severe disease (reviewed in [67]). In addition to alpha-1 antitrypsin deficiency, an 
established endotype of COPD, recent evidence identifies eosinophilic COPD as a new disease endotype marked by high sputum, blood or bronchoalveolar lavage fluid (BALF) eosinophil counts and responsiveness to ICS therapy [68]. As the field of endotyping continues to mature, the advent of high-throughput "-omics" technologies (epigenomics, genomics, transcriptomics, proteomics, metabolomics) $[69,70]$ and their application to respiratory diseases will undoubtedly further improve the resolution of endotyping and clarify the utility of other potential targets including type-17 factors, neutrophilic inflammation [71-75] and the microbiome [76-80]. One promising example from the European Unbiased Biomarkers for the Prediction of Respiratory Diseases Outcomes (U-BIOPRED) cohort has already utilised sputum proteomics and transcriptomics to reproducibly cluster asthma patients and similar strategies can be implemented in future studies of ACO [81].

\section{Risk factors for $\mathrm{ACO}$}

The aetiology of ACO most likely involves the interplay between various host and environmental factors, commencing from as early as fetal development and continuing into adulthood [82]. It is likely that ACO development requires innate predisposition including atopy, genetic factors evidenced by family history and newly identified genetic markers of risk (COPDGene studies) and exposure to risk factors, including rhinitis and respiratory infections, as well as exposure to cigarette smoke (CS) or air pollution [10, 82-86] for both asthma and COPD. Airway diseases that occur during early life or as a result of prenatal insults (including maternal smoking, poor nutrition), when lung development and immature pulmonary immunity are vulnerable to external assaults, can lead to impaired lung function in adulthood [87, 88]. Additionally, some patients with asthma may acquire an ACO phenotype by developing irreversible airflow obstruction possibly through progressive airway structural changes and remodelling [89-92]. Likewise, ageing is associated with reduced $\mathrm{FEV}_{1} / \mathrm{FVC}$ ratio and can contribute to fixed airflow obstruction in elderly asthmatics [93, 94]. Elucidating the genetic determinants of ACO may illuminate disease mechanisms and aid in the early diagnosis of at-risk patients. A genome-wide association study (GWAS) of non-Hispanic White and African American subjects failed to find significant differences in single nucleotide polymorphisms between patients with ACO and patients with COPD [95], and previous GWASs have yet to identify significant overlaps between asthma and COPD loci [96, 97]. Nevertheless, expression of disease-associated genes from the airway epithelium of patients with asthma are enriched among COPD cohorts, and subgroups of patients with COPD also exhibit increased type-2 responses [67]. Additionally, candidate gene studies have identified genes such as ADRB2, GSTM1, GSTP1, IL13, TGFB1 and TNF to be common between asthma and COPD [98], however, their roles in ACO remain to be elucidated.

\section{Current treatments}

The 2017 GINA/GOLD ACO guidelines recommend ICS as the first-line pharmacological intervention for the asthma component of ACO [9]. ICS reduce serum IgE and sputum eosinophils, and improves lung function and patient-reported symptom scores in some patients with ACO [21,99]. One study showed

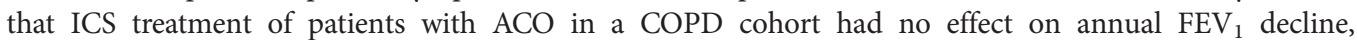
exacerbation rates or mortality [100]; however, the study design did not include eosinophil counts before/ after ICS treatment and therefore may not have captured truly ICS-sensitive groups. Bronchodilators, namely long-acting $\beta_{2}$ agonists (LABAs) and muscarinic antagonists (LAMAs), are mainstay treatments for COPD, and are often prescribed in conjunction with ICS to patients retrospectively identified to have ACO [101, 102]. Improved outcomes in terms of $\mathrm{FEV}_{1}$ were reported in patients with ACO versus patients with COPD following 3 months of ICS/LABA treatment [103]. In >250 000 patients with ACO, treatments with ICS/LABA and, interestingly, LAMA monotherapy, were both effective in reducing exacerbation rates [104]. However, there is a need for prospective studies that compare the responses and elucidate the predictors of responses of patients with ACO to combinations of ICS/LABA, ICS/LAMA, and ICS/LABA/ LAMA therapies in order to improve current treatment regimens and inform future clinical guidelines.

Acute exacerbations of ACO are managed based on established guidelines for asthma and COPD, which include treatment with short-acting $\beta_{2}$-agonists and systemic corticosteroids if symptomatic relief cannot be achieved with the former [105]. Omalizumab, a monoclonal antibody targeting free IgE, significantly improved spirometry outcomes in a small cohort of patients with ACO $(n=10)$ and reduced both eosinophilic (pre-omalizumab $10.36 \pm 4.25 \%$ to post-omalizumab $2.50 \pm 1.38 \%$ ) and neutrophilic (pre-omalizumab $38.79 \pm 14.6 \%$ to $29.65 \pm 9.7 \%$ ) airway inflammation [106]. Other prospective therapies including immunomodulatory macrolide antibiotics [107], cytokine inhibitors targeting IL-5, $-13,-17$ and -25 , and blockers of inflammatory pathways have been reviewed elsewhere $[10,108]$. While evidence supporting the use of these compounds in patients with ACO are yet to be demonstrated through clinical trials, it is imperative in the meantime that appropriate models/tools are developed to establish the feasibility and validity of the abovementioned therapeutics. 


\section{Animal models}

Complementary in vivo experiments maximise the translatability of findings from cell lines or primary human tissues and assist in the development of new treatments for patients. In vivo animal models are able to accommodate both local and systemic interactions of multifaceted diseases including ACO and thus are essential for: 1) investigating the complex interplay between different molecular pathways; and 2) designing and testing preventative strategies and drug treatments. So far, asthma and COPD have been widely modelled in numerous mammal species including rats, mice, guinea pigs, dogs and monkeys [109, 110]. Of these, mouse models have been critical for our understanding of disease-causing processes, identification of potential therapeutic targets and the development of novel biologics (e.g. anti-IL-5, anti-IL-13, anti-PD-1, anti-PDL1) $[65,73,111,112]$. While larger animals can accommodate human-comparable spirometry and drug-delivery procedures [113], smaller animals (e.g. mice) are advantageous in terms of lower costs for procurement, housing and rearing, as well as the abundance of deficient and transgenic strains and immunological tools, thereby making them a valuable starting point for modelling ACO.

$\mathrm{BALB} / \mathrm{c}$ and $\mathrm{C} 57 \mathrm{BL} / 6$ mice strains have intrinsic type-2- and type-1-biased immune responses, respectively [114-116]. BALB/c mice are more commonly used for allergic asthma models [117-121] due to their robust type-2 responses with increased expressions of IL-4, -5 , and -13 [122]. In several asthma studies comparing $\mathrm{BALB} / \mathrm{c}$ and $\mathrm{C} 57 \mathrm{BL} / 6$ strains, levels of serum $\operatorname{IgE}$ were generally higher in $\mathrm{BALB} / \mathrm{c}$ mice but eosinophil levels in BALF were comparable and sometimes higher in C57BL/6 mice [122-125]. Furthermore, there is a propensity for eosinophils to localise around the airways in BALB/c mice and be more evenly distributed in the lungs of C57BL/6 mice $[125,126]$. Despite these differences, long-term CS exposure (experimental COPD) has repeatedly produced comparable features in both strains in terms of recapitulating the hallmarks of human COPD. These include increased cell infiltrates in the lung parenchyma, tissue remodelling, emphysematous destruction and impaired lung function [127-133].

An approach to modelling the coexistence of asthma and COPD features is to induce both diseases in the same animal. This requires careful consideration of aetiological agents, as well as the order, route and timeframe of exposures. Based on protocols that have separately modelled asthma and COPD (reviewed in $[109,134-136])$, experimental allergic asthma is frequently induced using a combination of systemic sensitisation with ovalbumin (OVA) in the presence of an adjuvant (typically aluminium hydroxide) in order to elicit robust type-2 responses, which is followed by inhalation challenge with OVA to recruit the cells to the airways $[115,137,138]$, or with environmental allergens such as house dust mite (HDM) antigen (lung local sensitisation and challenge) that induce respiratory disease directly through the airways [139] and result in airway remodelling $[120,140]$. Common experimental models for COPD include acute or chronic exposure to CS, particulates, ozone, elastase, and lipopolysaccharide (LPS) [128-130, 133, 141]. Emphysema, a hallmark of COPD characterised by destruction of alveolar walls and airspace enlargement [142], has also been established in strains of transgenic mice as well as models with spontaneous mutations including the Tight Skin (impaired neonatal alveolar septation leading to emphysema) and Klotho mice (airspace enlargement and exaggerated ageing phenotype leading to emphysema-like changes) [143]. To recapitulate acute exacerbations [112], asthma models commonly use higher levels of the sensitising agent during challenge or through secondary respiratory infections and exposure to pollutants [144-146]. By comparison, COPD exacerbations have been modelled using intranasal administrations of LPS or viral and bacterial infections $[129,131,134]$. Therefore, careful consideration of the agents and sequence of exposures employed must be adopted for developing a model of ACO.

Additionally, gene-environment interactions are key contributors to the complexity of both asthma [147] and COPD [148] and are therefore likely important in ACO. Currently, robust gene signatures or GWAS studies of well-defined human ACO cohorts are yet to be obtained; however, genetic susceptibility is likely to contribute to the development of disease. This is critical in determining whether gene/environment interactions are important in the development and progression of ACO. However, interrogation of experimental models will contribute to answering these questions, and we propose that the sequence and duration of exposures and the strain of mice used will be important in translating experimental findings to different cohorts of patients.

\section{Animal studies of ACO}

Published animal studies on ACO are scarce, and only one study has explicitly investigated ACO using a murine model [149]. In this study, surfactant protein-D gene deletion in C57BL/6 (SP-D ${ }^{-1-}$ ) mice resulted in spontaneous development of emphysema and increased static lung compliance. Subsequent sensitisation and challenge with OVA in these mice significantly increased the expression of the mucin-encoding gene Muc5AC and induced goblet cell hyperplasia. Lower eosinophil counts and IL-5 and -13 levels were also observed in OVA-challenged SP-D ${ }^{-l-}$ mice compared with wild-type mice, which was partially attributed to the antigen-binding properties of SP-D. Notably, increased AHR was observed in allergic SP-D ${ }^{-/-}$mice 
compared with wild-type mice at a ventilation rate of 120 breaths per min, but not at 100 breaths per min. This frequency-dependent AHR was postulated by the authors to be a mechanism that may distinguish ACO from asthma and COPD. In this study, pathological features of COPD were induced via gene knockout and presented soon after birth, future studies may instead consider inducing disease at a later stage in life to better mirror the course of COPD in people. Additionally, the use of HDM antigen, a prevalent trigger of human allergies, may be given prior to the onset of COPD features in order to confirm the OVA results as well as model the early-onset nature of asthma typically observed in patients (figure 1).

\section{Considerations for future ACO animal models}

It has been shown that ACO features, including increased neutrophilic and/or eosinophilic inflammation [150] and irreversible airflow obstruction [151], can be found in patients with severe asthma. Steroid resistance, which contributes to mortality and morbidity in patients with severe asthma, is also induced by CS [152] in a substantial proportion of patients with ACO that currently smoke. These similarities have led to the proposal that ACO represents a form of severe asthma and models of severe asthma could potentially be adapted for studies on ACO $[153,154]$. Although caution must be taken to differentiate asthma with fixed airway obstruction from ACO in animal models. Current existing murine models of severe, steroid-resistant asthma [155-157] often involve sensitisation with OVA or HDM followed by the administration of IFN- $\gamma$ and/or LPS [158] or infections with bacterial (e.g. Chlamydia and Haemophilus) [159-162] or viral (e.g. influenza or respiratory syncytial virus) [163] agents. These protocols induce steroid resistance via multiple mechanisms including IL-27 and IFN- $\gamma$, microRNA responses, miR-21/ PTEN/PI3K/HDAC2 axis and inflammasome-mediated pathways, all of which can be targeted with inhibitors or attenuated using macrolides [111,112, 158, 160-162, 164]. Depending on the experimental method, the models demonstrate steroid resistance of key disease features including airway inflammation and AHR, as well as varying degrees of neutrophilic and/or eosinophilic inflammation. Similar observations have been made in HDM-sensitised mice with Atg5 deletion in CD11c cells (with impaired autophagy) [165]. Crucially, these experimental models are reminiscent of several phenotypes of ACO that have been described $[108,166]$ and provide the impetus to adapt severe asthma models as a viable approach to the study of ACO.

However, a history of cigarette smoking is a key driving factor in the development of persistent airflow limitation in individuals $\geqslant 40$ with early-life asthma [40]. Thus, incorporating CS exposure into models of experimental ACO is highly appropriate. Studies have investigated mice exposed to both CS and allergens such as OVA, HDM, LPS or cockroach antigen, either concurrently or sequentially (table 2). Acute exposures to allergens and CS promoted increased levels of type- 2 cytokines and inflammatory cells in BALF, with the exception of one study where addition of CS exposure for the last 2 weeks of a 5 week HDM model attenuated lung eosinophil levels [168]. Chronic CS exposure (10 weeks) robustly increased neutrophil numbers in the airways [172] and reproduced the pathology of neutrophilic airway inflammation in asthmatic smokers [173]. In addition, histone deacetylase 2 (HDAC2), which is required to mediate the anti-inflammatory effects of glucocorticoids, was found in one model to be reduced by CS exposure and partially restored (to levels of asthma alone) following treatment with the macrolide roxithromycin [172]. Whether HDAC pathways are altered in patients with ACO should therefore be assessed in future studies along with potential of macrolide therapy as an effective therapeutic option for ACO.

Until now, chronic exposures to OVA or HDM have been widely used to study the long-term effects of airway inflammation and remodelling observed in clinical asthma [120, 136, 140, 174]. Therefore, combining the most clinically relevant and representative components from both experimental asthma and CS-induced COPD models will likely generate the most human-relevant models of ACO. One such model developed by MeLgert et al. [175] employed male C57BL/6J mice exposed to OVA for 6 months with

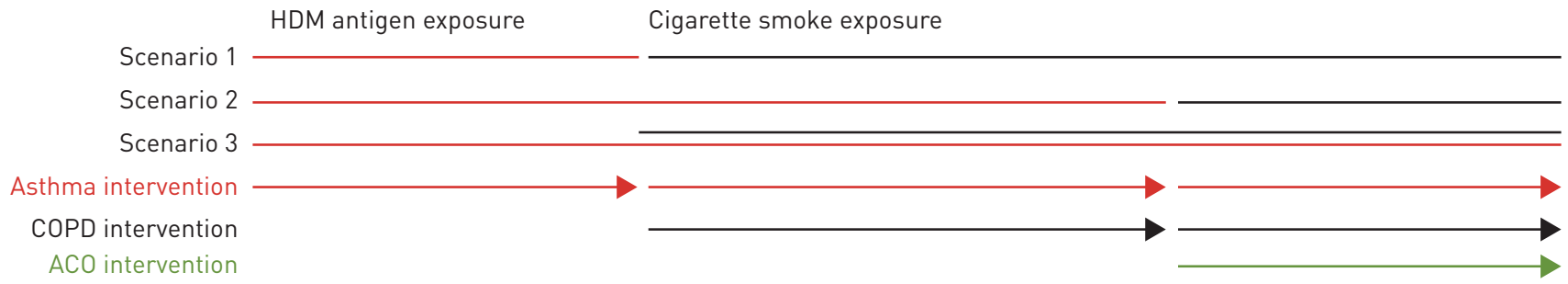

FIGURE 1 Potential mouse models for experimental asthma-COPD overlap (ACO). Scenario 1: experimental asthma with house dust mite antigen

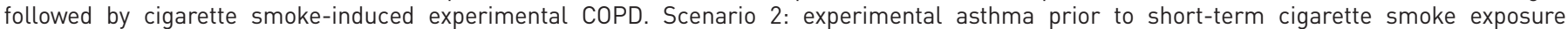

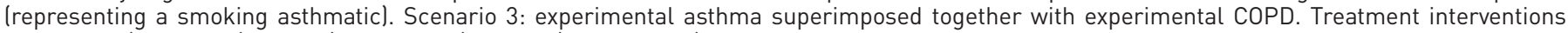
for asthma (red arrow), COPD (black arrow) or ACO (green arrow). 
TABLE 2 Murine models involving a combination of exposures to allergens and cigarette smoke (CS)

Strain Experimental method
Key features of model

\section{First author}

[ref.]

MoerLoose [167]

$\uparrow$ serum $\lg E$ and $\lg \mathrm{G} 1$

$\uparrow$ eosinophils, lymphocytes and dendritic cells in BALF

$\uparrow$ dendritic cells, goblet cell hyperplasia, CD4+ and

CD8+ T-cells in lung tissue

$\uparrow \mathrm{CCL} 17$ and IFN- $\gamma$ in BALF

$\uparrow$ IL-5 in lymph node cell cultures
BALB/c WT 3 weeks of HDM intranasally ( 5 days. week $^{-1}$ ) followed by 2 weeks of concurrent HDM+CS $\left(5\right.$ days $\cdot$ week $^{-1}, 12$ cigarettes for $50 \mathrm{~min}, 1$ or 2 times $\cdot$ day $^{-1}$ ) $\downarrow$ total cell count, mononuclear cells, neutrophils in BALF

$\downarrow$ eosinophils in BALF and lung tissue

$\downarrow$ B-cells and serum IgE

$\downarrow$ VCAM-1 and eotaxin-1

No significant differences in airway resistance

C57BL/6 WT 3 weeks of CS (5 days.week ${ }^{-1}, 5$ cigarettes 3 times day ${ }^{-1}$ ) No significant differences in AHR

and CD44

deficient with HDM intranasally once per week at the end of CS exposure
BALB/c WT Triple OVA, cockroach antigen, and HDM intraperitoneally on days 0,14 , and 21 followed by 6 weeks of allergen challenge concurrent with CS ( 5 days $\cdot$ week $^{-1}, 4$ cigarettes $\cdot$ day $^{-1}$ )

C57BL/6J WT LPS intranasally at days 0 and 14 followed by 10 weeks of CS 16 days $\cdot$ week $^{-1}, 9$ cigarettes for $2 \mathrm{~h}$, 2 times $\cdot$ day $^{-1}$ ) $\uparrow$ CD4+ and CD8+ T-cells, and hyaluronic acid in BALF

$\uparrow$ goblet cell metaplasia

$\uparrow$ IL-4, IL-5, IL-13 in lymph node cell culture

CD44 deletion resulted in:

$\circ \downarrow$ number of eosinophils, dendritic cells, neutrophils, CD4+ and CD8+ T-cells in BALF

$\circ \downarrow I L-4, I L-5$ and IL-13 in lymph node cell culture $\circ \downarrow$ goblet cell metaplasia

$\uparrow$ total cell count, eosinophils, macrophages, neutrophils, lymphocytes, IL-4 and IL-5; however, all except neutrophils were higher with allergen alone

$\uparrow I L-10, I L-12, I L-1 \beta$, and CXCL1 in BALF

$\downarrow$ compliance versus control following methacholine challenge, no increase in resistance observed

Impaired lung function

$\uparrow$ total cells counts in BALF $(\uparrow$ neutrophils, lymphocytes and macrophages)

$\uparrow \mathrm{IL}-6$ and $\mathrm{CXCL} 1$ in BALF

Goblet cell hyperplasia

Bronchial wall thickening

$\uparrow$ total cell count and $\uparrow \%$ of neutrophils in BALF

$X_{I A}[172]$

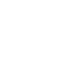

BALB/c WT OVA intraperitoneally on days 0 and 14. OVA aerosol administered daily from days 24 to 41 in conjunction to $\uparrow A H R$ CS (15 cigarettes for $40 \mathrm{~min}, 2$ times $\cdot$ day $^{-1}$ )

$\uparrow$ serum TNF- $\alpha$ and $\mathrm{CXCL} 1$

$\downarrow$ HDAC2 but $\uparrow$ phosphorylated Akt in lung sections measured using integrated optical density

BoteLHo [168] 


\section{Conclusions}

ACO has emerged as a significant clinical entity whereby the coexistence of asthma and COPD features increases the disease burden and challenges current diagnostic and therapeutic strategies. Elucidating the underlying mechanisms is challenging because of its complexity and heterogeneity, but may be achieved through alternative approaches such as defining and targeting treatable traits. However, it is essential in the meantime to develop animal models that best reflect the natural progression and pathophysiology of human ACO to improve the current understanding of key disease mechanisms and identify better diagnostic markers as well as targeted treatments. State-of-the-art technologies including “-omics”-based technologies will be invaluable in comprehensively characterising the important immune pathways, cell-to-cell interactions and structural and functional changes that occur in the lung during the development and progression of ACO. This will also provide insights into the driving factors of ACO compared with asthma or COPD alone. For these reasons, we anticipate that such models will expedite mechanistic discoveries and be relevant pre-clinical testing platforms for future investigations into the development of more effective and better-targeted therapies.

Acknowledgements: We thank Peter Gibson (Hunter Medical Research Institute and The University of Newcastle, Newcastle, Australia) and Christine Jenkins (Dept of Thoracic Medicine, Concord General Hospital, Sydney, Australia) for advice and input into the manuscript.

Support statement: C. Donovan is supported by National Health and Medical Research Council (NHMRC) Early Career Fellowship (1120152) and grant (1138402), R.Y. Kim is supported by a Boehringer Ingelheim Fellowship. P.M. Hansbro is supported by a NHMRC Principal Research Fellowship (1079187) and grants. Funding information for this article has been deposited with the Crossref Funder Registry.

Conflict of interest: None declared.

\section{References}

Lambrecht BN, Hammad H. The immunology of asthma. Nat Immunol 2015; 16: 45-56.

Borish L, Culp JA. Asthma: a syndrome composed of heterogeneous diseases. Ann Allergy Asthma Immunol 2008; 101: 1-9.

3 Hogg JC, Timens W. The pathology of chronic obstructive pulmonary disease. Annu Rev Pathol 2009; 4: 435-459.

4 Barnes PJ, Burney PG, Silverman EK, et al. Chronic obstructive pulmonary disease. Nat Rev Dis Primers 2015; 1: 15076.

5 Global Initiative for Asthma (GINA). Global strategy for asthma management and prevention. 2018. https:// ginasthma.org/wp-content/uploads/2018/04/wms-GINA-2018-report-V1.3-002.pdf

6 Global Initiative for Chronic Obstructive Lung Disease (GOLD). Global strategy for the diagnosis, management and prevention of COPD. 2019. https://goldcopd.org/wp-content/uploads/2018/11/GOLD-2019-v1.7-FINAL14Nov2018-WMS.pdf

7 Suzuki M, Makita H, Konno S, et al. Asthma-like features and clinical course of chronic obstructive pulmonary disease. An analysis from the Hokkaido COPD cohort study. Am J Respir Crit Care Med 2016; 194: 1358-1365.

8 Gibson PG, Simpson JL. The overlap syndrome of asthma and COPD: what are its features and how important is it? Thorax 2009; 64: 728-735.

9 Global Initiative for Asthma (GINA). Diagnosis and initial treatment of asthma, COPD and asthma-COPD overlap. 2017. https://ginasthma.org/asthma-copd-and-asthma-copd-overlap-syndrome-acos/

10 Leung JM, Sin DD. Asthma-COPD overlap syndrome: pathogenesis, clinical features, and therapeutic targets. BMJ 2017; 358: j3772.

11 Vos T, Abajobir AA, Abate KH, et al. Global, regional, and national incidence, prevalence, and years lived with disability for 328 diseases and injuries for 195 countries, 1990-2016: a systematic analysis for the Global Burden of Disease Study 2016. Lancet 2017; 390: 1211-1259.

12 Uchida A, Sakaue K, Inoue H. Epidemiology of asthma-chronic obstructive pulmonary disease overlap (ACO). Allergol Int 2018; 67: 165-171.

13 Menezes AMB, Montes de Oca M, Perez-Padilla R, et al. Increased risk of exacerbation and hospitalization in subjects with an overlap phenotype: COPD-asthma. Chest 2014; 145: 297-304.

14 Miravitlles M, Soriano JB, Ancochea J, et al. Characterisation of the overlap COPD-asthma phenotype. Focus on physical activity and health status. Respir Med 2013; 107: 1053-1060.

15 Kim M, Tillis W, Patel P, et al. Association between asthma-COPD overlap syndrome and healthcare utilizations among US adult population. Curr Med Res Opin 2019; 35: 1191-1196.

16 Barnes PJ. Asthma-COPD overlap. Chest 2016; 149: 7-8.

17 Gibson PG, McDonald VM. Asthma-COPD overlap 2015: now we are six. Thorax 2015; 70: 683-691.

18 Wardlaw AJ, Silverman M, Siva R, et al. Multi-dimensional phenotyping: towards a new taxonomy for airway disease. Clin Exp Allergy 2005; 35: 1254-1262.

19 Weatherall M, Travers J, Shirtcliffe PM, et al. Distinct clinical phenotypes of airways disease defined by cluster analysis. Eur Respir J 2009; 34: 812-818.

20 Jo KW, Ra SW, Chae EJ, et al. Three phenotypes of obstructive lung disease in the elderly. Int J Tuberc Lung Dis 2010; 14: 1481-1488.

21 Fingleton J, Travers J, Williams M, et al. Treatment responsiveness of phenotypes of symptomatic airways obstruction in adults. J Allergy Clin Immunol 2015; 136: 601-609.

22 Ghebre MA, Bafadhel M, Desai D, et al. Biological clustering supports both "Dutch" and "British" hypotheses of asthma and chronic obstructive pulmonary disease. J Allergy Clin Immunol 2015; 135: 63-72. 
Rootmensen G, van Keimpema A, Zwinderman A, et al. Clinical phenotypes of obstructive airway diseases in an outpatient population. J Asthma 2016; 53: 1026-1032.

24 Hirai K, Shirai T, Suzuki M, et al. A clustering approach to identify and characterize the asthma and chronic obstructive pulmonary disease overlap phenotype. Clin Exp Allergy 2017; 47: 1374-1382.

25 Bourdin A, Suehs CM, Marin G, et al. Asthma, COPD, and overlap in a national cohort: ACO on a gradient. J Allergy Clin Immunol 2018; 141: 1516-1518.

26 James AL, Wenzel S. Clinical relevance of airway remodelling in airway diseases. Eur Respir J 2007; 30: $134-155$.

27 Global Initiative for Asthma (GINA). Diagnosis of diseases of chronic airflow limitation: asthma, COPD and asthma-COPD overlap syndrome (ACOS). 2015. https://ginasthma.org/asthma-copd-and-asthma-copd-overlapsyndrome-acos/

Bourbeau J, Bhutani M, Hernandez P, et al. CTS position statement: pharmacotherapy in patients with COPD-An update. Can J Respir Crit Care Sleep Med 2017; 1: 222-241.

29 Yanagisawa S, Ichinose M. Definition and diagnosis of asthma-COPD overlap (ACO). Allergol Int 2018; 67: 172-178.

30 Kankaanranta H, Harju T, Kilpeläinen M, et al. Diagnosis and pharmacotherapy of stable chronic obstructive pulmonary disease: the Finnish guidelines. Basic Clin Pharmacol Toxicol 2015; 116: 291-307.

31 Plaza V, Alvarez F, Calle M, et al. Consensus on the asthma-COPD overlap syndrome (ACOS) between the Spanish COPD guidelines (GesEPOC) and the Spanish guidelines on the management of asthma (GEMA). Arch Bronconeumol 2017; 53: 443-449.

32 Cazzola M, Rogliani P. Do we really need asthma-chronic obstructive pulmonary disease overlap syndrome? J Allergy Clin Immunol 2016; 138: 977-983.

33 Kostikas K, Clemens A, Patalano F. The asthma-COPD overlap syndrome: do we really need another syndrome in the already complex matrix of airway disease? Int J Chron Obstruct Pulmon Dis 2016; 11: 1297-1306.

34 Rodrigo GJ, Neffen H, Plaza V. Asthma-chronic obstructive pulmonary disease overlap syndrome: a controversial concept. Curr Opin Allergy Clin Immunol 2017; 17: 36-41.

35 Perez-de-Llano L, Cosio BG, CHACOS study group. Asthma-COPD overlap is not a homogeneous disorder: further supporting data. Respir Res 2017; 18: 183.

36 Miravitlles M, Alvarez-Gutierrez FJ, Calle M, et al. Algorithm for identification of asthma-COPD overlap: consensus between the Spanish COPD and asthma guidelines. Eur Respir J 2017; 49: 1700068.

37 Soler-Cataluna JJ, Cosio B, Izquierdo JL, et al. Consensus document on the overlap phenotype COPD-asthma in COPD. Arch Bronconeumol 2012; 48: 331-337.

38 Koblizek V, Chlumsky J, Zindr V, et al. Chronic Obstructive Pulmonary Disease: official diagnosis and treatment guidelines of the Czech Pneumological and Phthisiological Society; a novel phenotypic approach to COPD with patient-oriented care. Biomed Pap Med Fac Univ Palacky Olomouc Czech Repub 2013; 157: 189-201.

39 Cosio BG, Soriano JB, Lopez-Campos JL, et al. Defining the Asthma-COPD overlap syndrome in a COPD cohort. Chest 2016; 149: 45-52.

40 Sin DD, Miravitlles M, Mannino DM, et al. What is asthma-COPD overlap syndrome? Towards a consensus definition from a round table discussion. Eur Respir J 2016; 48: 664-673.

41 Cataldo D, Corhay JL, Derom E, et al. A Belgian survey on the diagnosis of asthma-COPD overlap syndrome. Int J Chron Obstruct Pulmon Dis 2017; 12: 601-613.

42 Bonten TN, Kasteleyn MJ, de Mutsert R, et al. Defining asthma-COPD overlap syndrome: a population-based study. Eur Respir J 2017; 49: 1602008.

43 Mannino DM, Gan WO, Wurst K, et al. Asthma and chronic obstructive pulmonary disease overlap: the effect of definitions on measures of burden. Chronic Obstr Pulm Dis 2017; 4: 87-96.

44 Agusti A, Bel E, Thomas M, et al. Treatable traits: toward precision medicine of chronic airway diseases. Eur Respir J 2016; 47: 410-419.

45 Simpson AJ, Hekking PP, Shaw DE, et al. Treatable traits in the European U-BIOPRED adult asthma cohorts. Allergy 2019; 74: 406-411.

46 McDonald VM, Hiles SA, Godbout $\mathrm{K}$, et al. Treatable traits can be identified in a severe asthma registry and predict future exacerbations. Respirology 2019; 24: 37-47.

47 Pavord ID, Beasley R, Agusti A, et al. After asthma: redefining airways diseases. Lancet 2018; 391: 350-400.

48 Toledo-Pons N, van Boven JFM, Roman-Rodriguez M, et al. ACO: time to move from the description of different phenotypes to the treatable traits. PLoS One 2019; 14: e0210915.

49 Leung JM, Sin DD. Biomarkers in airway diseases. Can Respir J 2013; 20: 180-182.

50 Ramsahai JM, Simpson J, Wark P. Eosinophilia as a treatable trait in three patients with asthma and COPD. Respirol Case Rep 2018; 6: e00295.

51 Lipson DA, Barnhart F, Brealey N, et al. Once-daily single-inhaler triple versus dual therapy in patients with COPD. N Engl J Med 2018; 378: 1671-1680.

52 Bafadhel M, Peterson S, De Blas MA, et al. Predictors of exacerbation risk and response to budesonide in patients with chronic obstructive pulmonary disease: a post-hoc analysis of three randomised trials. Lancet Respir Med 2018; 6: 117-126.

53 Li W, Gao P, Zhi Y, et al. Periostin: its role in asthma and its potential as a diagnostic or therapeutic target. Respir Res 2015; 16: 57.

54 Tong X, Wang D, Liu S, et al. The YKL-40 protein is a potential biomarker for COPD: a meta-analysis and systematic review. Int J Chron Obstruct Pulmon Dis 2018; 13: 409-418.

55 Liu L, Zhang X, Liu Y, et al. Chitinase-like protein YKL-40 correlates with inflammatory phenotypes, anti-asthma responsiveness and future exacerbations. Respir Res 2019; 20: 95.

56 Shirai T, Hirai K, Gon Y, et al. Combined assessment of serum periostin and YKL-40 may identify asthma-COPD overlap. J Allergy Clin Immunol Pract 2019; 7: 134-145.

57 Katoh S, Ikeda M, Shirai R, et al. Biomarkers for differentiation of patients with asthma and chronic obstructive pulmonary disease. J Asthma 2018; 55: 1052-1058.

58 Shirai T, Hirai K, Gon Y, et al. Comparable serum periostin levels among a Japanese population with asthma, COPD, and asthma-COPD overlap. Eur Respir J 2017; 50: Suppl. 61, OA1480.

59 Gon Y, Maruoka S, Ito R, et al. Utility of serum YKL-40 levels for identification of patients with asthma and COPD. Allergol Int 2017; 66: 624-626. 
Iwamoto $\mathrm{H}$, Gao J, Koskela J, et al. Differences in plasma and sputum biomarkers between COPD and COPD-asthma overlap. Eur Respir J 2014; 43: 421-429.

61 Jo YS, Kwon SO, Kim J, et al. Neutrophil gelatinase-associated lipocalin as a complementary biomarker for the asthma-chronic obstructive pulmonary disease overlap. J Thorac Dis 2018; 10: 5047-5056.

62 Gao J, Iwamoto H, Koskela J, et al. Characterization of sputum biomarkers for asthma-COPD overlap syndrome. Int J Chron Obstruct Pulmon Dis 2016; 11: 2457-2465.

63 Lotvall J, Akdis CA, Bacharier LB, et al. Asthma endotypes: a new approach to classification of disease entities within the asthma syndrome. J Allergy Clin Immunol 2011; 127: 355-360.

64 Peters MC, Mekonnen ZK, Yuan S, et al. Measures of gene expression in sputum cells can identify TH2-high and TH2-low subtypes of asthma. J Allergy Clin Immunol 2014; 133: 388-394.

65 Hansbro PM, Scott GV, Essilfie AT, et al. Th2 cytokine antagonists: potential treatments for severe asthma. Expert Opin Investig Drugs 2013; 22: 49-69.

66 Anderson GP. Endotyping asthma: new insights into key pathogenic mechanisms in a complex, heterogeneous disease. Lancet 2008; 372: 1107-1119.

67 Christenson SA, Steiling K, van den Berge M, et al. Asthma-COPD overlap. Clinical relevance of genomic signatures of type 2 inflammation in chronic obstructive pulmonary disease. Am J Respir Crit Care Med 2015; 191: 758-766.

68 Tashkin DP, Wechsler ME. Role of eosinophils in airway inflammation of chronic obstructive pulmonary disease. Int J Chron Obstruct Pulmon Dis 2018; 13: 335-349.

69 Kan M, Shumyatcher M, Himes BE. Using omics approaches to understand pulmonary diseases. Respir Res 2017; 18: 149 .

70 Obeidat M, Dvorkin-Gheva A, Li X, et al. The overlap of lung tissue transcriptome of smoke exposed mice with human smoking and COPD. Sci Rep 2018; 8: 11881.

71 Agache I, Akdis CA. Endotypes of allergic diseases and asthma: an important step in building blocks for the future of precision medicine. Allergol Int 2016; 65: 243-252.

72 Russell DW, Wells JM, Blalock JE. Disease phenotyping in chronic obstructive pulmonary disease: the neutrophilic endotype. Curr Opin Pulm Med 2016; 22: 91-99.

73 Hansbro PM, Kaiko GE, Foster PS. Cytokine/anti-cytokine therapy - novel treatments for asthma? $B r J$ Pharmacol 2011; 163: 81-95.

74 Kim RY, Pinkerton JW, Gibson PG, et al. Inflammasomes in COPD and neutrophilic asthma. Thorax 2015; 70: 1199-1201.

75 Wang W, Li JJ, Foster PS, et al. Potential therapeutic targets for steroid-resistant asthma. Curr Drug Targets 2010; 11: 957-970.

76 Shukla SD, Budden KF, Neal R, et al. Microbiome effects on immunity, health and disease in the lung. Clin Transl Immunology 2017; 6: e133.

77 Huang YJ, Boushey HA. The microbiome in asthma. J Allergy Clin Immunol 2015; 135: 25-30.

78 Budden KF, Gellatly SL, Wood DL, et al. Emerging pathogenic links between microbiota and the gut-lung axis. Nat Rev Microbiol 2017; 15: 55-63.

79 Chotirmall SH, Gellatly SL, Budden KF, et al. Microbiomes in respiratory health and disease: an Asia-Pacific perspective. Respirology 2017; 22: 240-250.

80 Budden KF, Shukla SD, Rehman SF, et al. Functional effects of the microbiota in chronic respiratory disease. Lancet Respir Med 2019; 7: 907-920.

81 Lefaudeux D, De Meulder B, Loza MJ, et al. U-BIOPRED clinical adult asthma clusters linked to a subset of sputum omics. J Allergy Clin Immunol 2017; 139: 1797-1807.

82 Bateman ED, Reddel HK, van Zyl-Smit RN, et al. The asthma-COPD overlap syndrome: towards a revised taxonomy of chronic airways diseases? Lancet Respir Med 2015; 3: 719-728.

83 Hikichi M, Hashimoto S, Gon Y. Asthma and COPD overlap pathophysiology of ACO. Allergol Int 2018; 67: $179-186$.

84 To T, Zhu J, Larsen K, et al. Progression from asthma to chronic obstructive pulmonary disease. Is air pollution a risk factor? Am J Respir Crit Care Med 2016; 194: 429-438.

85 Gold MJ, Hiebert PR, Park HY, et al. Mucosal production of uric acid by airway epithelial cells contributes to particulate matter-induced allergic sensitization. Mucosal Immunol 2016; 9: 809-820.

86 Simpson JL, Baines KJ, Horvat JC, et al. COPD is characterized by increased detection of Haemophilus influenzae, Streptococcus pneumoniae and a deficiency of Bacillus species. Respirology 2016; 21: 697-704.

87 Martinez FD. The origins of asthma and chronic obstructive pulmonary disease in early life. Proc Am Thorac Soc 2009; 6: 272-277.

88 Stocks J, Sonnappa S. Early life influences on the development of chronic obstructive pulmonary disease. Ther Adv Respir Dis 2013; 7: 161-173.

89 Ulrik CS, Backer V. Nonreversible airflow obstruction in life-long nonsmokers with moderate to severe asthma. Eur Respir J 1999; 14: 892-896.

90 Vonk JM, Jongepier H, Panhuysen CI, et al. Risk factors associated with the presence of irreversible airflow limitation and reduced transfer coefficient in patients with asthma after 26 years of follow up. Thorax 2003; 58: $322-327$.

91 Pascual RM, Peters SP. The irreversible component of persistent asthma. J Allergy Clin Immunol 2009; 124: 883-890.

92 Meyer PA, Mannino DM, Redd SC, et al. Characteristics of adults dying with COPD. Chest 2002; 122: 2003-2008.

93 Sharma G, Goodwin J. Effect of aging on respiratory system physiology and immunology. Clin Interv Aging 2006; 1: 253-260.

94 Battaglia S, Benfante A, Spatafora M, et al. Asthma in the elderly: a different disease? Breathe (Sheff) 2016; 12: $18-28$.

95 Hardin M, Cho M, McDonald ML, et al. The clinical and genetic features of COPD-asthma overlap syndrome. Eur Respir J 2014; 44: 341-350.

96 Smolonska J, Koppelman GH, Wijmenga C, et al. Common genes underlying asthma and COPD? Genome-wide analysis on the Dutch hypothesis. Eur Respir J 2014; 44: 860-872. 
Hobbs BD, de Jong K, Lamontagne M, et al. Genetic loci associated with chronic obstructive pulmonary disease overlap with loci for lung function and pulmonary fibrosis. Nat Genet 2017; 49: 426-432.

98 Postma DS, Kerkhof M, Boezen HM, et al. Asthma and chronic obstructive pulmonary disease: common genes common environments? Am J Respir Crit Care Med 2011; 183: 1588-1594.

99 Feng JX, Lin Y, Lin J, et al. Relationship between fractional exhaled nitric oxide level and efficacy of inhaled corticosteroid in asthma-COPD overlap syndrome patients with different disease severity. J Korean Med Sci 2017; 32: 439-447.

100 Lim HS, Choi SM, Lee J, et al. Responsiveness to inhaled corticosteroid treatment in patients with asthma-chronic obstructive pulmonary disease overlap syndrome. Ann Allergy Asthma Immunol 2014; 113: 652-657.

101 Ding B, Small M. Treatment trends in patients with asthma-COPD overlap syndrome in a COPD cohort: findings from a real-world survey. Int J Chron Obstruct Pulmon Dis 2017; 12: 1753-1763.

102 Wurst KE, St Laurent S, Hinds D, et al. Disease burden of patients with asthma/COPD overlap in a US claims database: impact of ICD-9 coding-based definitions. COPD 2017; 14: 200-209.

103 Lee SY, Park HY, Kim EK, et al. Combination therapy of inhaled steroids and long-acting beta2-agonists in asthma-COPD overlap syndrome. Int J Chron Obstruct Pulmon Dis 2016; 11: 2797-2803.

104 Su VY, Yang KY, Yang YH, et al. Use of ICS/LABA combinations or LAMA is associated with a lower risk of acute exacerbation in patients with coexistent COPD and asthma. J Allergy Clin Immunol Pract 2018; 6: 1927-1935.

105 Kondo M, Tamaoki J. Therapeutic approaches of asthma and COPD overlap. Allergol Int 2018; 67: 187-190.

106 Yalcin AD, Celik B, Yalcin AN. Omalizumab (anti-IgE) therapy in the asthma-COPD overlap syndrome (ACOS) and its effects on circulating cytokine levels. Immunopharmacol Immunotoxicol 2016; 38: 253-256.

107 Simpson JL, Powell H, Baines KJ, et al. The effect of azithromycin in adults with stable neutrophilic COPD: a double blind randomised, placebo controlled trial. PLoS One 2014; 9: e105609.

108 Barnes PJ. Therapeutic approaches to asthma-chronic obstructive pulmonary disease overlap syndromes. J Allergy Clin Immunol 2015; 136: 531-545.

109 Aun MV, Bonamichi-Santos R, Arantes-Costa FM, et al. Animal models of asthma: utility and limitations. J Asthma Allergy 2017; 10: 293-301.

110 Ghorani V, Boskabady MH, Khazdair MR, et al. Experimental animal models for COPD: a methodological review. Tob Induc Dis 2017; 15: 25.

111 Li JJ, Wang W, Baines KJ, et al. IL-27/IFN-gamma induce MyD88-dependent steroid-resistant airway hyperresponsiveness by inhibiting glucocorticoid signaling in macrophages. J Immunol 2010; 185: 4401-4409.

112 Starkey MR, Jarnicki AG, Essilfie AT, et al. Murine models of infectious exacerbations of airway inflammation. Curr Opin Pharmacol 2013; 13: 337-344.

113 Meeusen EN, Snibson KJ, Hirst SJ, et al. Sheep as a model species for the study and treatment of human asthma and other respiratory diseases. Drug Discov Today Dis Models 2009; 6: 101-106.

114 Limjunyawong N, Craig JM, Lagasse HA, et al. Experimental progressive emphysema in BALB/cJ mice as a model for chronic alveolar destruction in humans. Am J Physiol Lung Cell Mol Physiol 2015; 309: L662-L676.

115 Kumar RK, Herbert C, Foster PS. The "classical" ovalbumin challenge model of asthma in mice. Curr Drug Targets 2008; 9: 485-494.

116 Gessner A, Blum H, Rollinghoff M. Differential regulation of IL-9-expression after infection with Leishmania major in susceptible and resistant mice. Immunobiology 1993; 189: 419-435.

117 Thorburn AN, Foster PS, Gibson PG, et al. Components of Streptococcus pneumoniae suppress allergic airways disease and NKT cells by inducing regulatory T cells. J Immunol 2012; 188: 4611-4620.

118 Preston JA, Essilfie AT, Horvat JC, et al. Inhibition of allergic airways disease by immunomodulatory therapy with whole killed Streptococcus pneumoniae. Vaccine 2007; 25: 8154-8162.

119 Thorburn AN, O’Sullivan BJ, Thomas R, et al. Pneumococcal conjugate vaccine-induced regulatory $\mathrm{T}$ cells suppress the development of allergic airways disease. Thorax 2010; 65: 1053-1060.

120 Liu G, Cooley MA, Nair PM, et al. Airway remodelling and inflammation in asthma are dependent on the extracellular matrix protein fibulin-1c. J Pathol 2017; 243: 510-523.

121 Nair PM, Starkey MR, Haw TJ, et al. Targeting PP2A and proteasome activity ameliorates features of allergic airway disease in mice. Allergy 2017; 72: 1891-1903.

122 Gueders MM, Paulissen G, Crahay C, et al. Mouse models of asthma: a comparison between C57BL/6 and $\mathrm{BALB} / \mathrm{c}$ strains regarding bronchial responsiveness, inflammation, and cytokine production. Inflamm Res 2009; 58: 845-854.

123 Van Hove CL, Maes T, Cataldo DD, et al. Comparison of acute inflammatory and chronic structural asthma-like responses between C57BL/6 and BALB/c mice. Int Arch Allergy Immunol 2009; 149: 195-207.

124 Shinagawa K, Kojima M. Mouse model of airway remodeling: strain differences. Am J Respir Crit Care Med 2003; 168: 959-967.

125 Takeda K, Haczku A, Lee JJ, et al. Strain dependence of airway hyperresponsiveness reflects differences in eosinophil localization in the lung. Am J Physiol Lung Cell Mol Physiol 2001; 281: L394-L402.

126 Lu Y, Sjostrand M, Malmhall C, et al. New production of eosinophils and the corresponding TH1/TH2 balance in the lungs after allergen exposure in BALB/c and C57BL/6 mice. Scand J Immunol 2010; 71: 176-185.

127 Beckett EL, Stevens RL, Jarnicki AG, et al. A new short-term mouse model of chronic obstructive pulmonary disease identifies a role for mast cell tryptase in pathogenesis. J Allergy Clin Immunol 2013; 131: $752-762$.

128 Liu G, Cooley MA, Jarnicki AG, et al. Fibulin-1 regulates the pathogenesis of tissue remodeling in respiratory diseases. JCI Insight 2016; 1: e86380.

129 Hsu AC, Dua K, Starkey MR, et al. MicroRNA-125a and -b inhibit A20 and MAVS to promote inflammation and impair antiviral response in COPD. JCI Insight 2017; 2: e90443.

130 Franklin BS, Bossaller L, De Nardo D, et al. The adaptor ASC has extracellular and 'prionoid' activities that propagate inflammation. Nat Immunol 2014; 15: 727-737.

131 Hsu AC, Starkey MR, Hanish I, et al. Targeting PI3K-p110alpha suppresses influenza virus infection in chronic obstructive pulmonary disease. Am J Respir Crit Care Med 2015; 191: 1012-1023. 
132 Haw TJ, Starkey MR, Pavlidis S, et al. Toll-like receptor 2 and 4 have opposing roles in the pathogenesis of cigarette smoke-induced chronic obstructive pulmonary disease. Am J Physiol Lung Cell Mol Physiol 2018; 314: L298-L317.

133 Hansbro PM, Hamilton MJ, Fricker M, et al. Importance of mast cell Prss31/transmembrane tryptase/tryptase- $\gamma$ in lung function and experimental chronic obstructive pulmonary disease and colitis. J Biol Chem 2014; 289: 18214-18227.

134 Jones B, Donovan C, Liu G, et al. Animal models of COPD: what do they tell us? Respirology 2017; 22: 21-32.

135 Stevenson CS, Birrell MA. Moving towards a new generation of animal models for asthma and COPD with improved clinical relevance. Pharmacol Ther 2011; 130: 93-105.

136 Nials AT, Uddin S. Mouse models of allergic asthma: acute and chronic allergen challenge. Dis Model Mech 2008; $1: 213-220$.

137 Starkey MR, Essilfie AT, Horvat JC, et al. Constitutive production of IL-13 promotes early-life Chlamydia respiratory infection and allergic airway disease. Mucosal Immunol 2013; 6: 569-579.

138 Starkey MR, Nguyen DH, Essilfie AT, et al. Tumor necrosis factor-related apoptosis-inducing ligand translates neonatal respiratory infection into chronic lung disease. Mucosal Immunol 2014; 7: 478-488.

139 Johnson JR, Wiley RE, Fattouh R, et al. Continuous exposure to house dust mite elicits chronic airway inflammation and structural remodeling. Am J Respir Crit Care Med 2004; 169: 378-385.

140 Burgess JK, Boustany S, Moir LM, et al. Reduction of tumstatin in asthmatic airways contributes to angiogenesis, inflammation, and hyperresponsiveness. Am J Respir Crit Care Med 2010; 181: 106-115.

141 Russell KE, Chung KF, Clarke CJ, et al. The MIF antagonist ISO-1 attenuates corticosteroid-insensitive inflammation and airways hyperresponsiveness in an ozone-induced model of COPD. PLoS One 2016; 11: e0146102.

142 Sharafkhaneh A, Hanania NA, Kim V. Pathogenesis of emphysema: from the bench to the bedside. Proc Am Thorac Soc 2008; 5: 475-477.

143 Tuder RM, McGrath S, Neptune E. The pathobiological mechanisms of emphysema models: what do they have in common? Pulm Pharmacol Ther 2003; 16: 67-78.

144 Kumar RK, Herbert C, Foster PS. Mouse models of acute exacerbations of allergic asthma. Respirology 2016; 21: 842-849.

145 Gualano RC, Hansen MJ, Vlahos R, et al. Cigarette smoke worsens lung inflammation and impairs resolution of influenza infection in mice. Respir Res 2008; 9: 53.

146 Donovan C, Seow HJ, Bourke JE, et al. Influenza A virus infection and cigarette smoke impair bronchodilator responsiveness to beta-adrenoceptor agonists in mouse lung. Clin Sci (Lond) 2016; 130: 829-837.

147 von Mutius E. Gene-environment interactions in asthma. J Allergy Clin Immunol 2009; 123: 3-11.

148 Sandford AJ, Silverman EK. Chronic obstructive pulmonary disease. 1: susceptibility factors for COPD the genotype-environment interaction. Thorax 2002; 57: 736-741

149 Tamura K, Matsumoto K, Fukuyama S, et al. Frequency-dependent airway hyperresponsiveness in a mouse model of emphysema and allergic inflammation. Physiol Rep 2018; 6: e13568.

150 Wenzel SE, Schwartz LB, Langmack EL, et al. Evidence that severe asthma can be divided pathologically into two inflammatory subtypes with distinct physiologic and clinical characteristics. Am J Respir Crit Care Med 1999; 160: 1001-1008.

151 Zhang L, He L, Gong J, et al. Risk factors associated with irreversible airway obstruction in asthma: a systematic review and meta-analysis. Biomed Res Int 2016; 2016: 9868704

152 Thomson NC, Chaudhuri R, Livingston E. Active cigarette smoking and asthma. Clin Exp Allergy 2003; 33: $1471-1475$.

153 Xia Y, Cao Y, Xia L, et al. Severe asthma and asthma-COPD overlap: a double agent or identical twins? J Thorac Dis 2017; 9: 4798-4805.

154 de Marco R, Marcon A, Rossi A, et al. Asthma, COPD and overlap syndrome: a longitudinal study in young European adults. Eur Respir J 2015; 46: 671-679.

155 Maltby S, Tay HL, Yang M, et al. Mouse models of severe asthma: understanding the mechanisms of steroid resistance, tissue remodelling and disease exacerbation. Respirology 2017; 22: 874-885.

156 Kim RY, Rae B, Neal R, et al. Elucidating novel disease mechanisms in severe asthma. Clin Transl Immunology 2016; 5: e91.

157 Hansbro PM, Kim RY, Starkey MR, et al. Mechanisms and treatments for severe, steroid-resistant allergic airway disease and asthma. Immunol Rev 2017; 278: 41-62.

158 Yang M, Kumar RK, Foster PS. Pathogenesis of steroid-resistant airway hyperresponsiveness: interaction between IFN-gamma and TLR4/MyD88 pathways. J Immunol 2009; 182: 5107-5115.

159 Ito K, Herbert C, Siegle JS, et al. Steroid-resistant neutrophilic inflammation in a mouse model of an acute exacerbation of asthma. Am J Respir Cell Mol Biol 2008; 39: 543-550.

160 Kim RY, Pinkerton JW, Essilfie AT, et al. Role for NLRP3 inflammasome-mediated, IL-1beta-dependent responses in severe, steroid-resistant asthma. Am J Respir Crit Care Med 2017; 196: 283-297.

161 Kim RY, Horvat JC, Pinkerton JW, et al. MicroRNA-21 drives severe, steroid-insensitive experimental asthma by amplifying phosphoinositide 3-kinase-mediated suppression of histone deacetylase 2. J Allergy Clin Immunol 2017; 139: 519-532.

162 Essilfie AT, Horvat JC, Kim RY, et al. Macrolide therapy suppresses key features of experimental steroid-sensitive and steroid-insensitive asthma. Thorax 2015; 70: 458-467.

163 Lukacs NW, Tekkanat KK, Berlin A, et al. Respiratory syncytial virus predisposes mice to augmented allergic airway responses via IL-13-mediated mechanisms. J Immunol 2001; 167: 1060-1065.

164 Nguyen TH, Maltby S, Tay HL, et al. Identification of IFN-gamma and IL-27 as critical regulators of respiratory syncytial virus-induced exacerbation of allergic airways disease in a mouse model. J Immunol 2018; 200: $237-247$

165 Suzuki Y, Maazi H, Sankaranarayanan I, et al. Lack of autophagy induces steroid-resistant airway inflammation. J Allergy Clin Immunol 2016; 137: 1382-1389.

166 Putcha N, Wise RA. Asthma-chronic obstructive pulmonary disease overlap syndrome: nothing new under the sun. Immunol Allergy Clin North Am 2016; 36: 515-528. 
Moerloose KB, Robays LJ, Maes T, et al. Cigarette smoke exposure facilitates allergic sensitization in mice. Respir Res 2006; 7: 49 .

168 Botelho FM, Llop-Guevara A, Trimble NJ, et al. Cigarette smoke differentially affects eosinophilia and remodeling in a model of house dust mite asthma. Am J Respir Cell Mol Biol 2011; 45: 753-760.

169 Kumar S, Lanckacker E, Dentener M, et al. Aggravation of allergic airway inflammation by cigarette smoke in mice is CD44-dependent. PLoS One 2016; 11: e0151113.

170 Tilp C, Bucher H, Haas H, et al. Effects of conventional tobacco smoke and nicotine-free cigarette smoke on airway inflammation, airway remodelling and lung function in a triple allergen model of severe asthma. Clin Exp Allergy 2016; 46: 957-972.

171 Shu J, Li D, Ouyang H, et al. Comparison and evaluation of two different methods to establish the cigarette smoke exposure mouse model of COPD. Sci Rep 2017; 7: 15454.

172 Xia M, Xu H, Dai W, et al. The role of HDAC2 in cigarette smoke-induced airway inflammation in a murine model of asthma and the effect of intervention with roxithromycin. J Asthma 2018; 55: 337-344.

173 Chalmers GW, MacLeod KJ, Thomson L, et al. Smoking and airway inflammation in patients with mild asthma. Chest 2001; 120: 1917-1922.

174 Wegmann M. Animal models of chronic experimental asthma - strategies for the identification of new therapeutic targets. J Occup Med Toxicol 2008; 3: Suppl. 1, S4.

175 Melgert BN, Timens W, Kerstjens HA, et al. Effects of 4 months of smoking in mice with ovalbumin-induced airway inflammation. Clin Exp Allergy 2007; 37: 1798-1808. 